\title{
Chemistry in Africa: A Joint AAPAC-IUPAC Meeting 11 July 1998, Durban, South Africa
}

On the occasion of the Seventh International Chemistry Conference in Africa, 5-10 July, 1998, Prof. Joshua Jortner, the current President of IUPAC, and Prof. E. D. Bekoe, the current President of the African Association for Pure and Applied Chemistry (AAPAC) convened a conference of African chemistry leaders with representatives of IUPAC. In the extraordinarily effective one-day meeting, held on 11 July 1998, the participants discussed problems facing the African chemical enterprise and suggested solutions that could be implemented jointly by IUPAC and AAPAC.

Present were Drs. B. M. Abegaz (Botswana), E. A. Aboutabl (Egypt), I. Addae-Mensah (Ghana), B. I. Alo (Nigeria), E. D. Becker (United States), D. A. Bekoe (Ghana), M. D. Booth (South Africa), J. D. Bradley (South Africa), E. L. J. Breet (South Africa), L. Diop (Senegal), E. K. Farraq (Egypt), F. Gasengayire (Kenya), C. F. Garbers (South Africa), J. Jortner (Israel), B. T. Kiremire (Uganda), E. M. R. Kiremire (South Africa), J. M. Malin (United States), C. C. Mjojo (South Africa), T. T. Mokoena (Botswana), J. L. Moswa (Democratic Republic of the Congo), V. S. B. Mtetwa (Swaziland), T. Nyokong (South Africa), J. I. Okogun (Nigeria), H. M. Salem (Egypt), P. S. Steyn (South Africa), S. O. Wandiga (Kenya), and N. S. Youssef (Egypt).

Purposes of the meeting. Host organizer Professor Pieter S. Steyn greeted the participants by noting that the purposes of the meeting were to improve communications between IUPAC and AAPAC, to assist IUPAC in finding a specific role to contribute to Chemistry in Africa, and to help find a route to technologybased development in Africa. Dr. Steyn noted with thanks that the financial sponsors of the meeting were IUPAC, the Foundation for Research Development, Merck, and SASOL Ltd.

Comments by Prof. Joshua Jortner, President of IUPAC, on the strategy of IUPAC to serve the global chemistry community. In welcoming all present, Professor Jortner explained that IUPAC's mission will increasingly involve concentration on the globalization of the scientific-technological endeavor and on recent advances in science and technology. He added that IUPAC will respond to the challenges in the mission-oriented service of chemistry to meet mankind's needs.

Prof. Jortner outlined IUPAC's five-point plan for development in the 21 st century. IUPAC will work to strengthen access in developing countries to information and research networks in chemistry and related

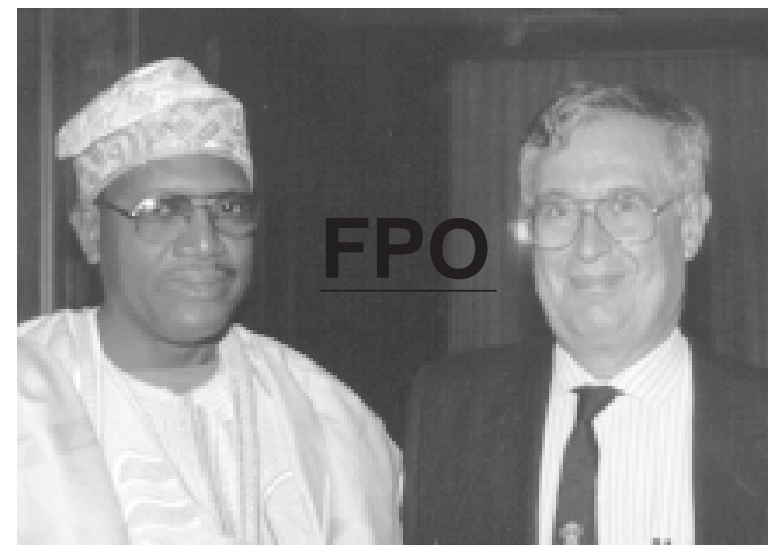

Professors B. I. Alo and J. Jortner

fields, to build capacity of developing countries for chemical research, to enhance human educational resources in developing countries, to foster the abilities of developing countries to adapt recent scientific and technological advances to local conditions and needs, and to augment cooperation with regional scientific academies in developing countries.

Prof. Jortner noted that solutions to African problems must be urgently sought, given the impetus of globalization, scientific and technological advances, new information technology, and burgeoning population growth. He pointed out that scientists in developing countries will count increasingly on advances in electronic communication that can dramatically reduce the geographic and political barriers, isolation, and fragmentation that have hampered them in the past. He noted that the keys to success will be found in obtaining needed equipment, training, useful contacts, functioning access to electronic networks, databases and publications, and long-term maintenance and support of networks and equipment.

Prof. Jortner suggested that IUPAC can contribute by helping African chemical scientists to formulate and prioritize their own needs, to emphasize institutional capacity, including management and maintenance, to establish long-term interinstitutional relationships rather than "hit-and-run" short-term studies and assistance, and to realize the potential for increased regional and subregional cooperation.

Comments by Prof. D. A. Bekoe on the role and function of AAPAC in promoting chemistry on the African continent. Prof. Bekoe reminded the participants that the role of the AAPAC, i.e., to foster chemical research and the application of chemistry and allied sciences to capacity building in Africa, is quite 


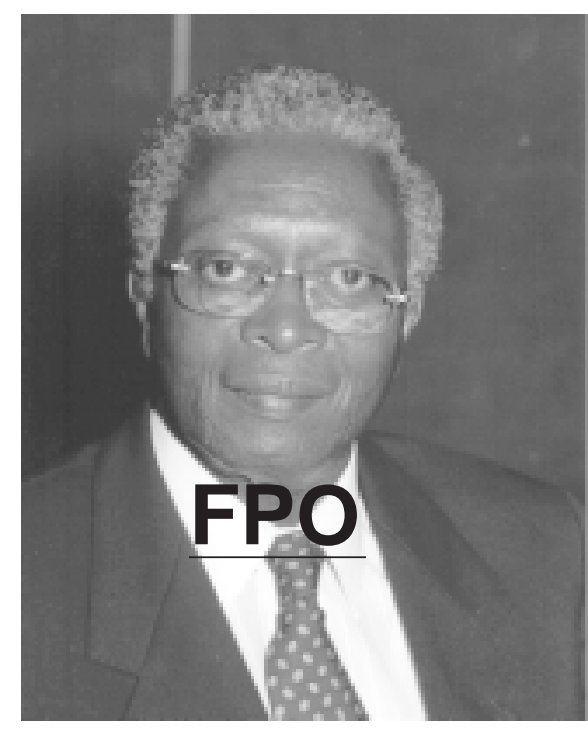

Professor D. A. Bekoe

congruent with the goals of IUPAC. He noted the special problems caused in Africa by population growth. In regard to food production, for example, new lands are brought into cultivation only after the old lands have been exhausted. Prof. Bekoe added that research funding in some countries is weak and getting weaker, having in some cases been reduced by two-thirds. Even so, AAPAC is developing opportunities for joint efforts to obtain support by giving chemical researchers a voice with governments.

Prof. Bekoe suggested that AAPAC can help promote teaching and learning in ways unique to Africa. The solutions sought should be Africa-relevant because learning strategies and cost-effective solutions are not necessarily the same in all parts of the world. Through the International Chemistry Conference in Africa (ICCA) series, AAPAC has already established a dialogue on chemical education. AAPAC discussions on environmental chemistry, theoretical chemistry, and natural products chemistry are stimulating young researchers. Now those new scientists will need access to faster, modern methods of obtaining and analyzing data.

Prof. Bekoe noted that AAPAC and IUPAC both have long-term objectives to foster chemical research and the application of chemistry and allied sciences, with special emphasis on capacity building. Therefore, he said, it is necessary that there be liaison between the two organizations with the goals of (1) strengthening of national chemical associations in the region, (2) working together to encourage chemistry-related industry, particularly large industry, to contribute to sustainable development, creation of wealth, and improvement of the quality of life in Africa, (3) finding ways to work with and learn from IUPAC and other bodies such as ICSU, COSTED, UNIDO and UNESCO, (4) improving the resource base of AAPAC, and (5) developing more effective scientific communications in the region.

\section{Status of Chemistry on the African Continent}

Only two countries in Africa-Egypt and South Africa-are members of IUPAC. There is clearly a need to increase African participation. Prof. Jortner, quoting from an excellent report written for IUPAC by Dr. C. F. Garbers, noted that while Africa includes $62 \%$ of the world's developing countries, the distribution of development is not homogeneous. Some 29 of the 51 countries published less than 10 abstracted journal articles in 1996, while Egypt published 2560 in the same year. Among the 45 countries in sub-Saharan Africa, only 3 countries produced the great majority of published research articles in chemistry. They were South Africa (1359 abstracts), Nigeria (384 abstracts), and Kenya (97 abstracts). No abstracts were cited from 5 countries and another 21 countries produced less than 10 abstracts each. Rising university enrollments (mostly in the Arts) and stagnant budgets have caused average per-student expenditures to fall from $\$ 6,300$ in 1970 to $\$ 1,500$ by 1988 .

Dr. Garbers recommended that if IUPAC wishes to embark on further initiatives, a detailed study should be made of an area which is served by so many agencies. He noted that the Committee on Teaching of Chemistry has new and important initiatives to contribute. He suggested that IUPAC, being active in all fields of chemistry and with extensive expertise in publication, could become involved in the preparation of texts for training and reference in selected fields of importance in developing countries. These might include water quality, human health, food analysis, and access to chemical information. Also, the work of CHEMRAWN should be extended to techno-economic analysis of countries and regions to identify potential industrial and market initiatives.

Dr. Garbers noted further that, while neither IUPAC or UNESCO is a major funding organization, together they have the ability to provide direction-giving inputs. One possible approach is outlined in the recommendations made by the recent report of the IUPAC Task Team of African Chemists convened in 1997. The Task Team recommended that IUPAC/UNESCO coordinate a Pan-African chemistry development project, implementing recommendations that will come from a series of five regional workshops. The workshops will involve all African countries, which will be invited to assess the types of support and other inputs necessary. Major funding will be sought from local governments and national and international development agencies.

Dr. Garbers emphasized that there is a tendency to 